\title{
Language background in early life may be related to neuropsychiatry symptoms in patients with Alzheimer disease
}

\author{
Yi-Chien Liu ${ }^{1,2,3}$, Jung-Lung Hsu' ${ }^{6}$, Shuu-Jin Wang ${ }^{4,5}$, Ping-Keung Yip ${ }^{1,3}$, Kenichi Meguro ${ }^{2,4^{*}+}$
} and Jong-Ling Fuh ${ }^{4,5^{*}+}$

\begin{abstract}
Background: The relationship between early life experience and the occurrence of neuropsychiatry symptoms (NPSs) in patients with Alzheimer disease (AD) is unclear.

Methods: From 2012 to 2014, we prospectively recruited 250 patients with probable AD from the memory clinic of Taipei Veterans General Hospital. All patients underwent standard assessments, including brain magnetic resonance imaging or computed tomography, neuropsychological tests, neuropsychiatry inventory (NPI-Q) and related blood tests. A linear regression analysis was performed to investigate the relationship between NPSs and age, gender, disease severity, depression, language background (with or without Japanese education).

Results: Among the 250 participants, 113 (45.2\%) were women. Their average age was 82.6 years. Of all the participants, 93 (37.2\%) had received formal Japanese education, whereas 157 (62.8\%) did not receive Japanese education. The participants with Japanese education were slightly younger $(83.1 \pm 3.6$ vs. $81.4 \pm 3.4, P=0.006)$, with a higher proportion of them were women $(30.5 \%$ vs. $69.8 \%, P<0.001)$ and fewer years of total education $(10.8 \pm 4.5 \mathrm{vs}$. $7.7 \pm 3.2, P<0.001)$, compared to the participants without Japanese education. NPI-Q scores significantly differed between the two groups (15.8 vs. 24.1, $P=0.024$ ). Both disease severity and language background predicted NPI-Q scores.

Conclusions: Language background in early life may be related to NPSs in patients with AD, and this effect is more significant in patients with a lower education level than in those with a higher education level. More NPSs may be the result of negative effects on dominant language or early life experiences.
\end{abstract}

Keywords: Language background, Dementia, Alzheimer's disease, Neuropsychiatry symptoms, Language impairment

\section{Background}

Neuropsychiatric symptoms (NPSs), which can be psychotic (delusions and hallucinations), affective (apathy, depressed mood, irritability and anxiety) and, behavioral (euphoria, disinhibition, agitation, aberrant motor activities, sleep disturbance and eating disorder), are the core symptoms of Alzheimer disease (AD) [1]. NPSs is once thought to emerge in people with advanced stage. But it is currently found to manifest in prodromal and all stage

\footnotetext{
*Correspondence: k-meg@umin.ac.jp; jfuh@vghtpe.gov.tw

${ }^{\dagger}$ Equal contributors

${ }^{2}$ Division of Geriatric Behavioral Neurology, CYRIC, Tohoku University, Sendai, Japan

${ }^{4}$ Department of Neurology, Neurological Institute, Taipei Veterans General Hospital, Taipei, Taiwan

Full list of author information is available at the end of the article
}

of AD. Besides, NPSs is related to rapid cognitive decline, caregiver distress and early institutionalization [2]. In a previous study, the prevalence of NPSs in patients with AD was approximately about $30-40 \%$ [3]; the incidence was ranging from 20 to $30 \%$ every year [4]. If untreated patients of $\mathrm{AD}$ are also considered, the prevalence of NPSs may be as high as 77.8\% [5]. Many risk factors for NPSs have been proposed, including biological factors such as age, sex, race, disease severity, and general medical condition. The severity of dementia has been consistently related to NPSs in most studies $[3,6]$. However, the findings of studies on these biological risk factors sometimes have been inconsistent or even contradictory [4]. In addition to biological risk factors, studies have emphasized environmental 
or psychosocial effects on individuals [7-10]. Some studies have described both biological and environmental effects. In a study which recruited 137 elderly Chinese American and 140 Caucasians with and without cognitive impairment from a referral memory clinic found depression was significantly more common in cognitively impaired Chinese Americans compared with cognitively impaired Caucasians. Besides, Chinese Americans were less likely to be on treatment for depression than Caucasians. In that case, depression is not only related to biological factors such as ethnicity but also environmental factors like education and culture [11]. However, few studies have focused on the linkage between early language experience and NPSs in dementia.

In addition to NPSs, AD impairs patients' cognitive function in multiple domains. Language impairment is one of the earliest and most common symptoms [12]. It often causes communication problems and burdens caregivers [13]. Studies have indicated that language impairment in patients with AD may subsequently lead them to attempt to use languages they used in their childhood or even neologisms [14, 15].

Before World War II (WW II), many Taiwanese people received formal Japanese education in their childhood. Thus, in contrast to their Taiwanese peers who may have received their education after the war or on the mainland, these Taiwanese people can speak Japanese. Moreover, Japanese became their first symbolic language. After the war, the official language of Taiwan was changed to Mandarin Chinese. Therefore, the Japanese speaking ability of Taiwanese people who received formal Japanese education remained at a low fluency level. In everyday life, most members of this group still speak Taiwanese or Mandarin Chinese.

In our previous pilot study, we recruited 21 patients with $\mathrm{AD}$ from a memory clinic. We observed that multilingual patients with $\mathrm{AD}$ experienced more delusions. Moreover, "language mixing" and "inappropriate emotional response" are believed to be the possible origins of delusions [16]. This study further examined this theory by using a more comprehensive design and including a large sample-size cohort.

\section{Methods \\ Participants}

We prospectively recruited 250 patients with $\mathrm{AD}$ from the outpatient clinic of Taipei Veterans General Hospital between August 2012 and July 2014. All patients were diagnosed as having AD by a multidisciplinary consensus meeting. The diagnosis of probable AD was made in accordance with the National Institute on Aging-Alzheimer's Association (NIA-AA) criteria [17]. The disease duration was defined as the period between the initial symptoms reported by a caregiver or a family member and patients' first visit.

The inclusion criteria included; 1) Patients who were proficient in Mandarin Chinese and were able to complete all our examinations in Chinese; and 2) $\mathrm{Pa}$ tients had to undergo a series of standard assessments, including a detailed clinical dementia history-taking, brain MRI or CT, laboratory tests, and neuropsychological tests. The exclusion criteria included; 1 ) Patients who were illiterate and aged less than 76 years (those younger than 76 years did not have the chance to receive formal Japanese education); 2) Patients with any possible reversible cause of dementia; and 3) Patients with a history of psychiatric diseases such as schizophrenia.

This study was approved by Ethics Committee of the Taipei Veterans General Hospital, Taipei, Taiwan. Informed consent was obtained from the patients and their family.

\section{Language status of participants}

Most participants in our study who had received Japanese education were capable of using Taiwanese, Japanese and Mandarin Chinese in their daily life. They did not encounter any problems while communicating with other people and understood word meanings in each language. Japanese was the first symbolic language they had learned. Thus, they had continued to watch TV, listen to the radio, and write letters to their friends in Japanese. By contrast, age-matched controls could fluently use only Taiwanese or Mandarin Chinese. They had not received any education in Japanese. Most of them used Mandarin Chinese in everyday life, including in business, government information or letterwriting contexts. In a previous community-based study, we reported a relationship between this complex language environment and dementia prevalence [18].

\section{MRI analysis and rating scales}

Of all participants, 132 (52.8\%) underwent whole-brain MRI (GE, 3 T DISCOVERY 750, GE Taiwan) in the clinical assessment. Trans-axial T2 weighted scans, 3D fluidattenuated inversion recovery images, and high-resolution sagittal T1-weighted images were acquired. The image analysis included a visual rating of medial temporal lobe atrophy (MTA) and posterior cortical atrophy (PA) on T1-weighted images. MTA was rated on a 5-point scale ( 0 point, absent; 1 point, minimal; 2 points, mild; 3 points, moderate; and 4 points, severe) on the basis of the height of hippocampal formation and the width of the choroid fissure and the temporal horn [19]. PA was rated on a 4-point scale ( 0 point, absent; 1 point, mild sulcal widening and mild atrophy; 2 points, substantial widening and atrophy; and 3 points, severe atrophy) on the basis of the posterior cingulate and parieto-occipital 
sulcus and the sulci of the parietal lobes and precuneus [20]. To confirm the consistency of the aforementioned rating methods, several cases were selected and evaluated through a consensus meeting of neurologists.

\section{Neuropsychological assessment Mini-mental status examination}

To evaluate general objective cognitive function, we performed the Mini-Mental Status Examination (MMSE). We used the Mandarin Chinese version of the MMSE which had been translated and validated by one of our authors [21]. The MMSE sub-items were calculated as follows: orientation to time and place (10 points), immediate registration ( 3 points), attention (5 points), delayed recall ( 3 points), language ( 5 points, including naming, repeating phrase, reading and writing), following a three-step command (3 points), and copying a figure (1 point).

\section{Clinical dementia rating scale and clinical dementia rating scale Sum of boxes}

We evaluated the functional severity of dementia by using the Clinical Dementia Rating (CDR) scale. All clinical information was provided by patients' caregivers. The CDR Scale Sum of Boxes (CDR-SOB) scores were calculated by adding six domains of functioning scores (memory, orientation, judgement and problem solving, community affairs, home and hobbies, and personal care) [22].

\section{Chinese version of the Boston naming test}

To assess the language ability of participants, we used the 15-item Mandarin Chinese Version of the Boston Naming Test (C-BNT) [23] during the initial visit.

\section{Neuropsychiatric inventory questionnaire}

The neuropsychiatric inventory questionnaire (NPI-Q) was administered to examine the frequency and severity of NPSs [24, 25]. All NPI subscales were used in this study, namely delusion, hallucination, agitation, depression, anxiety, euphoria, apathy, disinhibition, irritability, aberrant motor behaviors, sleep disturbances, and eating disturbances. Each subscale score was calculated as the sum of items' severity (1-3).

\section{Geriatric depression scale}

We used the 15-item Geriatric Depression Scale (GDS) [26] to evaluate the depression status of our participants.

\section{Statistical analysis}

All analyses were performed using the Statistical Package for Social Sciences, Version 22 (SPSS, Chicago, IL, USA). Demographic variables were compared using Student's $t$ test and the chi-square test when appropriate. A linear regression analysis was performed using NPI-Q scores as the outcome variable and age, sex, CDR-SOB scores, GDS, and language background as predicting variables. To eliminate the possible confounding bias of education and its related effects, we stratified our cases according to whether their education levels were low ( $<9$ years) or high ( $\geq 9$ years). Nine years of education was the median and mean in our total population. All data used in the analysis are provided in the supporting information.

\section{Results}

\section{Demographic characteristics of the participants}

Of the 250 participants, $113(45.2 \%)$ were women. The average age and the average age and education level of the participants were 82.6 and 9.7 years, respectively. Their disease duration was 48.8 months. Furthermore, 93 (37.2\%) participants had received formal Japanese education. The disease severity was similar between the participants with and without Japanese education (Table 1). The MMSE and C-BNT scores did not differ between the two groups (Table 2). Likewise, the disease duration did not differ between them. The participants with Japanese education were slightly younger $(83.1 \pm 3.6$ vs. $81.4 \pm 3.4, P=0.006)$, with a higher proportion of them were women $(30.5 \%$ vs. $69.8 \%, P<0.001)$ and fewer years of total education $(10.8 \pm 4.5$ vs. $7.7 \pm 3.2, P<$ 0.001 ), compared to the participants without Japanese education (Table 1). The GDS scores were similar in the two groups. However, the NPI-Q scores were significantly higher among the participants with Japanese education than among the participants without Japanese education $(24.1 \pm 33.5$ vs. $15.8 \pm 23.6, P=0.024)$.

\section{Results of regression analysis}

Overall, disease severity (CDR-SOB) and language background both predicted the NPI-Q scores of the participants $(P=0.021$ and 0.021 respectively; Table 3 , Model $1)$. After stratification was conducted, language background significantly predicted the NPI-Q scores of the low-education group $(P=0.014$; Table 3 , Model 2). In the high-education group, disease severity (CDR-SOB) significantly predicted NPI-Q scores $(P=0.012$; Table 3 , Model 3).

\section{NPI-Q and MMSE sub-item analysis}

Subsequent analysis indicated a difference in behavioral symptoms mainly in delusion ( 3.1 vs. $1.9, P=0.043$ ), depression (2.1 vs. $1.2, P=0.033)$ and anxiety (2.6 vs. 1.3 , $P=0.004)$, between the participants with and without Japanese education (Table 4). A further analysis of MMSE sub-items demonstrated that participants with Japanese education scored lower on language-related items (4.0 vs. $4.4, P=0.001$; Table 5 ). 
Table 1 Demographic and clinical data of all the study participants and comparison between those with and without Japanese education

\begin{tabular}{lllll}
\hline & $\begin{array}{l}\text { All subjects } \\
(n=250)\end{array}$ & $\begin{array}{l}\text { With Japanese } \\
\text { education } \\
(n=93)\end{array}$ & $\begin{array}{l}\text { Without } \\
\text { Japanese } \\
\text { education } \\
(n=157)\end{array}$ & $P$ value \\
\hline Age & $82.6 \pm 3.5$ & $81.4 \pm 3.4$ & $83.1 \pm 3.6$ & $0.006^{*}$ \\
Female $(n, \%)$ & $113(45.2 \%)$ & $65(69.8 \%)$ & $48(30.5 \%)$ & $<0.001^{*}$ \\
Education (years) & $9.7 \pm 4.3$ & $7.7 \pm 3.2$ & $10.8 \pm 4.5$ & $<0.001^{*}$ \\
MMSE & $18.9 \pm 4.8$ & $18.9 \pm 4.7$ & $18.8 \pm 4.9$ & 0.964 \\
CDR (n, \%) & & & & \\
1 & $193(77.2 \%)$ & $72(77.5 \%)$ & $121(77.1 \%)$ & 0.473 \\
2 & $50(20 \%)$ & $20(21.5 \%)$ & $30(19.1 \%)$ & \\
3 & $7(2.8 \%)$ & $1(1.1 \%)$ & $6(3.8 \%)$ & \\
CDR-SOB & $6.7 \pm 3.0$ & $6.6(2.5)$ & $6.8(3.2)$ & 0.636 \\
$\begin{array}{l}\text { Disease duration } \\
\text { (months) }\end{array}$ & $48.8 \pm 45.5$ & $45.6 \pm 46.5$ & $50.7 \pm 44.9$ & 0.390 \\
\hline
\end{tabular}

Note: MMSE Mini-Mental State Examination, CDR Clinical Dementia Rating Scale, CDR-SOB Clinical Dementia Rating Scale Sum of Boxes scores

The $p$-value stand for results of comparison between with/without Japanese education, ${ }^{*}$ for $p<0.05$, Values are mean \pm SD and number (\%)

\section{MRI results}

The results of the MRI visual rating scale revealed no differences in MTA and PA between the participants with and without Japanese education (MTA scores: 4.2 \pm 1.6 vs. $4.0 \pm 1.5, P=0.663$; PA scores: $2.8 \pm 1.2$ vs. $2.6 \pm$ $1.0, P=0.195)$.

\section{Discussion}

The results of this study revealed that the Taiwanese patients with AD who had received Japanese education in childhood might have more NPSs than do those who did not receive Japanese education. The relationship was more significant among the patients with AD who had a low educational level. The difference in NPSs between these two groups was confined to the domains of delusion, depression and anxiety. At the same time, we observed that the patients with $\mathrm{AD}$ who had received Japanese education obtained lower language-related MMSE sub-item scores than did their counterparts.

Table 2 Comparison of the results of neuropsychological tests of the study participants with and without Japanese education

\begin{tabular}{lcccc}
\hline & $\begin{array}{l}\text { All subjects } \\
(n=250)\end{array}$ & $\begin{array}{l}\text { With Japanese } \\
\text { education } \\
(n=93)\end{array}$ & $\begin{array}{l}\text { Without Japanese } \\
\text { education } \\
(n=157)\end{array}$ & $P$ value \\
\hline GDS & $3.9 \pm 3.3$ & $3.9 \pm 3.1$ & $3.9 \pm 3.4$ & 0.889 \\
C-BNT & $11.6 \pm 2.5$ & $11.6 \pm 2.5$ & $11.6 \pm 2.5$ & 0.948 \\
NPI-Q total & $18.9 \pm 27.9$ & $24.1 \pm 33.5$ & $15.8 \pm 23.6$ & $0.024^{*}$
\end{tabular}

Note: GDS Geriatric Dementia Scale, C-BNT Chinese Version of the Boston Naming Test, NPI-Q Neuropsychiatric Inventory Questionnaire

The $p$-value stand for results of comparison between with/without Japanese education, ${ }^{*}$ for $p<0.05$, Values are mean \pm SD
Table 3 Linear regression models of NPI-Q scores and Japanese education for all, lower level of education and higher level of education

\begin{tabular}{|c|c|c|c|c|}
\hline Predictor & $\beta$ & Standard error & $T$ & $P$ value \\
\hline \multicolumn{5}{|c|}{ Model 1 (All subjects, $n=250$ ) } \\
\hline Age & -0.001 & 0.496 & -0.015 & 0.988 \\
\hline Gender $^{a}$ & -0.004 & 3.746 & -0.064 & 0.949 \\
\hline GDS & 0.039 & 0.512 & 0.615 & 0.539 \\
\hline CDR-SOB & 0.148 & 0.611 & 2.328 & $0.021^{*}$ \\
\hline Japanese education ${ }^{\mathrm{b}}$ & 0.159 & 3.833 & 2.320 & $0.021^{*}$ \\
\hline \multicolumn{5}{|c|}{ Model 2 (Low educational group, $n=140$ ) } \\
\hline Age & 0.013 & 0.725 & 0.148 & 0.883 \\
\hline Gender & -0.073 & 5.438 & -0.832 & 0.407 \\
\hline GDS & 0.041 & 0.785 & 0.485 & 0.628 \\
\hline CDR-SOB & 0.076 & 0.956 & 0.882 & 0.379 \\
\hline Japanese education & 0.220 & 5.367 & 2.499 & $0.014^{*}$ \\
\hline \multicolumn{5}{|c|}{ Model 3 (High educational group, $n=110$ ) } \\
\hline Age & -0.001 & 0.633 & -0.012 & 0.990 \\
\hline Gender & 0.149 & 5.305 & 1.365 & 1.175 \\
\hline GDS & 0.013 & 0.617 & 0.135 & 0.892 \\
\hline CDR-SOB & 0.246 & 0.717 & 2.559 & $0.012^{*}$ \\
\hline Japanese education & -0.064 & 5.653 & -0.596 & 0.552 \\
\hline
\end{tabular}

MMSE Mini-Mental State Examination, CDR-SOB Clinical Dementia Rating Scale Sum of Boxes scores, GDS Geriatric Dementia Scale

Note: Gender ${ }^{\mathrm{a}}: 0=$ male, $1=$ female, Japanese education ${ }^{\mathrm{b}}: 0=$ Without

Japanese education, $1=$ With Japanese education, $\beta=$ unstandardized beta coefficient, $T=$ test statistics

${ }^{*}$ for $p<0.05$, Subjects received education $\geqq 9$ years were classified as higheducational group, $<9$ years as low-educational group, 9 years of education was the median and mean of total subjects

Table 4 Comparison of NPI-Q sub-items of the study participants with and without Japanese education

\begin{tabular}{lccc}
\hline & $\begin{array}{c}\text { With Japanese } \\
\text { education }(n=93)\end{array}$ & $\begin{array}{c}\text { Without Japanese } \\
\text { education }(n=157)\end{array}$ & $P$ value \\
\hline NPI-Q total & $24.1 \pm 3.4$ & $15.8 \pm 1.8$ & $0.024^{*}$ \\
Delusion & $3.1 \pm 4.8$ & $1.9 \pm 4.0$ & $0.043^{*}$ \\
Hallucination & $1.0 \pm 2.6$ & $1.0 \pm 3.1$ & 0.954 \\
Agitation & $2.4 \pm 4.2$ & $1.6 \pm 3.3$ & 0.103 \\
Depression & $2.1 \pm 4.0$ & $1.2 \pm 2.3$ & $0.033^{*}$ \\
Anxiety & $2.6 \pm 4.1$ & $1.3 \pm 2.9$ & $0.004^{*}$ \\
Euphoria & $0.6 \pm 2.3$ & $1.3 \pm 2.9$ & 0.213 \\
Apathy & $1.9 \pm 3.8$ & $1.3 \pm 2.8$ & 0.168 \\
Disinhibition & $2.1 \pm 3.9$ & $1.3 \pm 3.1$ & 0.060 \\
Irritability & $2.8 \pm 4.5$ & $1.9 \pm 3.5$ & 0.072 \\
Aberrant behaviors & $1.8 \pm 3.4$ & $1.2 \pm 3.2$ & 0.226 \\
Sleep disturbance & $2.0 \pm 3.8$ & $1.3 \pm 3.0$ & 0.111 \\
Loss of appetite & $1.2 \pm 2.9$ & $1.0 \pm 3.0$ & 0.566 \\
\hline
\end{tabular}

${ }^{*}$ for $p<0.05$, Values are mean \pm SD 
Table 5 Comparison of MMSE sub-items of the study participants with and without Japanese education

\begin{tabular}{lccc}
\hline & $\begin{array}{l}\text { With Japanese } \\
\text { education }(n=93)\end{array}$ & $\begin{array}{c}\text { Without Japanese } \\
\text { education }(n=157)\end{array}$ & $P$ value \\
\hline MMSE total & $18.9 \pm 4.7$ & $18.8 \pm 4.9$ & 0.964 \\
Orientation & $5.1 \pm 2.2$ & $4.7 \pm 2.4$ & 0.159 \\
Immediate registration & $2.8 \pm 0.5$ & $2.9 \pm 0.3$ & 0.437 \\
Attention & $2.8 \pm 1.6$ & $2.6 \pm 1.9$ & 0.336 \\
Delayed recall & $0.8 \pm 1.0$ & $0.7 \pm 1.0$ & 0.700 \\
Three-step command & $1.9 \pm 0.9$ & $1.9 \pm 1.1$ & 0.875 \\
Language & $4.0 \pm 0.9$ & $4.4 \pm 0.8$ & $0.001^{*}$ \\
Copying figure & $0.6 \pm 0.4$ & $0.6 \pm 0.4$ & 0.920 \\
\hline${ }^{*}$ for $p<0.05$, Values are mean \pm SD & &
\end{tabular}

Our study results can be attributed to the effects of "language mixing", which we have demonstrated in a previous pilot study [16]. Our participants had received formal Japanese education for approximately 6 years in their childhood. Although Japanese was their first symbolic language, they used Taiwanese or Mandarin Chinese in most of their daily life. In other words, they were generally unbalanced multilinguals. When they developed dementia, each language may not have degenerated in parallel [27], and they tended to communicate with other people through mixed language [28]. Subsequently, more misunderstanding and inappropriate emotional responses might have been induced. In a previous study, we illustrated this phenomenon by including several typical cases. In the current study, we found that fluctuation because of communication problems might have resulted in more delusion, depression and anxiety in our patients with AD. The combination of these behavioral symptoms has also been described in dementia patients with impaired language function, and delusion has been associated with early life experience [29].

Our results can also be possibly attributed to chronic stress in this group of people with unique life experiences. After WWII, the official language of Taiwan was changed from Japanese to Mandarin Chinese. Thus, people who had received Japanese education were relatively isolated and had fewer opportunities for jobs and education. Chronic stress has been regarded as a risk factor for $\mathrm{AD}$ [30], potentially increasing the incidence or accelerating the appearance of it. A longitudinal study reported that, patients with more self-reported psychological stress in midlife developed $\mathrm{AD}$ in late-life in a population-based sample followed for 35 years [31]. In animal studies, inflammation and glucose metabolism were used to explain the underlying mechanism [32]. In our study, more NPSs could also be regarded as an early and a crucial sign of rapid cognitive decline in the future [33].
In this study, the GDS (self-reported), which was conducted during patients' first visit did not reveal that they were more depressed than another group of people; however, the sub-item analysis of the NPI-Q (completed by their family or caregivers) suggested that the patients were more depressed. A discrepancy was observed between the two scores. This discrepancy may be attributed to the difference between their sense of themselves and sense of their family or caregiver.

The linkage between NPSs and AD is very complex and is not yet fully understood. Many possible mechanisms have been proposed [34]: 1) NPS may reflect a common underlying brain pathology as AD; 2) NPS may share a common risk factor with AD; 3) NPS may be a psychological reaction caused by cognitive decline due to AD; and 4) NPS may synergistically interact with other biological factors and cause rapid decline linked with AD.

\section{Conclusion}

In this study, we found that early life language experience in childhood may be related to more NPSs in dementia in late life. Language mixing and chronic stress may have contributed to the results. However, the relationship between NPSs and AD remain unclear. We may partially answer this question after following our patients for a longer time in future studies.

\section{Limitations}

In this study, we did not examine the socioeconomic status of our participants, which is also a very crucial part of early life experiences. Discrepancy in socioeconomic status might partially explain our results. In our cohort, most patients with Japanese education were women. This was taken into consideration after we included sex as a predictor variable in the regression analysis. However, depression was found to be more prevalent in female patients with dementia previous studies. Thus, the results of our NPI-Q sub-items analysis should be interpreted more carefully. In this study, our subjects are not "pure" monolinguals. Most of them speak mandarin Chinese and Taiwanese even without Japanese education. We may need one more group of "monolingual" $\mathrm{AD}$ patients to illustrate the effects of language on NPSs.

\section{Additional file}

Additional file 1: All the statistic results of this study can be calculated from our additional file 1 (XLS $368 \mathrm{~kb}$ )

Acknowledgments

None. 


\section{Funding}

The study was supported by grants from Academia Sinica of Taiwan (Taiwan Biobank: Biosignature study of Alzheimer's disease); the Ministry of Science and Technology of Taiwan (104-2314-B-075 -005 -MY2, 104-2745-B-075 -001 -); Taipei Veterans General Hospital (V105C-110, V105E9-001-MY2-1); the Ministry of Science and Technology support for the Centre for Dynamical Biomarkers and Translational Medicine, National Central University, Taiwan (MOST 1032911-I-008-001); the Brain Research Center, National Yang-Ming University; and the Ministry of Education Aim for the Top University Plan.

\section{Availability of data and materials}

The dataset analyzed in the current study is available in the Additional file 1.

\section{Authors' contributions}

KM and JLF planned the survey and contributed to interpreting the research data. YCL contributed to writing and revising the manuscript. JLH contributed to interpreting the research data. SJW and PKY contributed to interpreting the research data and revising the manuscript. All authors read and approved the final manuscript.

\section{Competing interests}

The authors declare that they have no competing interests.

\section{Consent for publication}

Not applicable.

\section{Ethics approval and consent to participate}

This study was approved by Ethics Committee of the Taipei Veterans General Hospital, Taipei, Taiwan. Informed consent was obtained from the patients and their family. If patients were unable to sign the consent, written informed consent would be obtained from their guardian or close family member.

\section{Author details}

${ }^{1}$ Neurological Center of Cardinal Tien Hospital, Taipei, Taiwan. ${ }^{2}$ Division of Geriatric Behavioral Neurology, CYRIC, Tohoku University, Sendai, Japan. ${ }^{3} \mathrm{Fu}$ Jen University School of Medicine, Taipei, Taiwan. ${ }^{4}$ Department of Neurology, Neurological Institute, Taipei Veterans General Hospital, Taipei, Taiwan. ${ }^{5}$ Faculty of Medicine and Brain Research Center, National Yang-Ming University Schools of Medicine, Taipei, Taiwan. ${ }^{6}$ Section of Dementia and Cognitive impairment, Department of Neurology, Chang Gung Memorial Hospital, Linkou 112, Taiwan.

\section{Received: 12 October 2016 Accepted: 25 January 2017} Published online: 10 February 2017

\section{References}

1. Rosenberg PB, Mielke MM, Appleby BS, Oh ES, Geda YE, Lyketsos CG. The Association of Neuropsychiatric Symptoms in MCI with Incident Dementia and Alzheimer Disease. Am J Geriatr Psychiatry. 2013;21(7):685-95. doi:10.1016/j.jagp.2013.01.006.

2. Gilley DW, Bienias JL, Wilson RS, Bennett DA, Beck TL, Evans DA. Influence of Behavioral Symptoms on Rates of Institutionalization for Persons with Alzheimer's Disease. Psychol Med. 2004;34(6):1129-35.

3. Apostolova LG, Di LJ, Duffy EL, Brook J, Elashoff D, Tseng C-H, Fairbanks L, Cummings JL. Risk Factors for Behavioral Abnormalities in Mild Cognitive Impairment and Mild Alzheimer's Disease. Dement Geriatr Cogn Disord. 2014:37(5-6):315-26. doi:10.1159/000351009.

4. Steinberg M, Corcoran C, Tschanz JT, Huber C, Welsh-Bohmer K, Norton MC, Zandi P, Breitner JCS, Steffens DC, Lyketsos CG. Risk Factors for Neuropsychiatric Symptoms in Dementia: The Cache County Study. Int J Geriatr Psychiatry. 2006;21(9):824-30. doi:10.1002/gps.1567.

5. Spalletta G, Musicco M, Padovani A, Rozzini L, Perri R, Fadda L, Canonico V, et al. Neuropsychiatric Symptoms and Syndromes in a Large Cohort of Newly Diagnosed, Untreated Patients with Alzheimer Disease. Am J Geriatr Psychiatry. 2010;18(11):1026-35. doi:10.1097/JGP.0b013e3181d6b68d.

6. Vilalta-Franch J, López-Pousa S, Calvó-Perxas L, Garre-Olmo J. Psychosis of Alzheimer Disease: Prevalence, Incidence, Persistence, Risk Factors, and Mortality. Am J Geriatr Psychiatry. 2013;21(11):1135-43. doi:10.1016/j.jagp.2013.01.051.
7. Hong G-RS, Song J-A. Relationship between Familiar Environment and Wandering Behaviour among Korean Elders with Dementia. J Clin Nurs. 2009;18(9):1365-73. doi:10.1111/j.1365-2702.2008.02566.x.

8. Auguste N, Federico D, Dorey J-M, Sagne A, Thomas-Antérion C, Rouch I, Laurent B, Gonthier R, Girtanner C. Role of personality, familial environment, and severity of the disease on the behavioral and psychological symptoms of dementia. Psychol Neuropsychiatr Vieil. 2006;4(3):227-35.

9. Osborne H, Simpson J, Stokes G. The Relationship between Pre-Morbid Personality and Challenging Behaviour in People with Dementia: A Systematic Review. Aging Ment Health. 2010;14(5):503-15. doi:10.1080/ 13607861003713208.

10. Rouch I, Dorey J-M, Boublay N, Henaff M-A, Dibie-Racoupeau F, Makaroff Z, Harston S, et al. Personality, Alzheimer's Disease and Behavioural and Cognitive Symptoms of Dementia: The PACO Prospective Cohort Study Protocol. BMC Geriatr. 2014;14:110. doi:10.1186/1471-2318-14-110.

11. Chao SZ, Matthews BR, Yokoyama JS, Lai NB, Ong H, Tse M, Yuan RF, et al. Depressive Symptoms in Chinese-American Subjects with Cognitive Impairment. Am J Geriatr Psychiatry. 2014;22(7):642-52. doi:10.1016/j.jagp.2012.10.029.

12. Kempler D, Goral M. LANGUAGE AND DEMENTIA: NEUROPSYCHOLOGICAL ASPECTS. Ann Rev Appl Linguist. 2008;28:73-90. doi:10.1017/S0267190508080045.

13. Potkins D, Myint P, Bannister C, Tadros G, Chithramohan R, Swann A, O'Brien J, et al. Language Impairment in Dementia: Impact on Symptoms and Care Needs in Residential Homes. Int J Geriatr Psychiatry. 2003;18(11):1002-6. doi:10.1002/gps. 1002.

14. Klimova B, Maresova P, Valis M, Hort J, Kuca K. Alzheimer's Disease and Language Impairments: Social Intervention and Medical Treatment. Clin Interv Aging. 2015;10:1401-8. doi:10.2147/CIA.S89714.

15. Manenti R, Repetto C, Bentrovato S, Marcone A, Bates E, Cappa SF. The Effects of Ageing and Alzheimer's Disease on Semantic and Gender Priming. Brain. 2004;127(10):2299-306. doi:10.1093/brain/awh264.

16. Liu Y-C, Yen-Ying L, Ping-Keung Y, Kyoko A, Kenichi M. "More Delusions May Be Observed in Low-Proficient Multilingual Alzheimer's Disease Patients." Edited by Dezhong Yao. PLoS ONE. 2015;10(11):e0140714. doi:10.1371/ journal.pone.0140714.

17. McKhann Guy M, Knopman DS, Howard C, Hyman BT, Jack CR, Kawas CH, Klunk WE, et al. The Diagnosis of Dementia due to Alzheimer's Disease: Recommendations from the National Institute on Aging-Alzheimer's Association Workgroups on Diagnostic Guidelines for Alzheimer's Disease. Alzheimers Dement. 2011;7(3):263-69. doi:10.1016/j.jalz.2011.03.005.

18. Liu, Yi-Chien, Yen-Ying Liu, Ping-Keung Yip, Mitsue Meguro and Kenichi Meguro. "Speaking one more language in early life has only minor effects on cognition in Taiwanese with low education level: The Taishan Project". Psychogeriatrics. 2016. (In press)

19. Duara R, Loewenstein DA, Potter E, Appel J, Greig MT, Urs R, Shen Q, et al. Medial Temporal Lobe Atrophy on MRI Scans and the Diagnosis of Alzheimer Disease. Neurology. 2008;71(24):1986-92. doi:10.1212/01.wnl. 0000336925.79704.9f.

20. Koedam Esther LGE, Manja L, van der Flier WM, Philip S, Yolande AL P, Nick F, Frederik B, Wattjes MP. Visual Assessment of Posterior Atrophy Development of a MRI Rating Scale. Eur Radiol. 2011;21(12):2618-25. doi:10.1007/s00330-011-2205-4

21. Shyu YI, Yip PK. Factor Structure and Explanatory Variables of the MiniMental State Examination (MMSE) for Elderly Persons in Taiwan. J Formos Med Assoc. 2001;100(10):676-83.

22. O'Bryant SE, Waring SC, Munro Cullum C, Hall J, Lacritz L, Massman PJ, Lupo PJ, Reisch JS, Doody R. Staging Dementia Using Clinical Dementia Rating Scale Sum of Boxes Scores. Arch Neurol. 2008;65(8):1091-95. doi:10.1001/archneur.65.8.1091.

23. Chen $T-B$, Lin $C-Y$, Lin $K-N$, Yeh $Y-C$, Chen $W-T$, Wang $K-S$, Wang P-N. Culture Qualitatively but Not Quantitatively Influences Performance in the Boston Naming Test in a Chinese-Speaking Population. Dement Geriatr Cogn Disord. 2014;4(1):86-94. doi:10.1159/000360695.

24. Fuh J-L, Liu C-K, Mega MS, Wang S-J, Cummings JL. Behavioral Disorders and Caregivers' Reaction in Taiwanese Patients With Alzheimer's Disease. Int Psychogeriatr. 2001;13(01):121-28. doi:10.1017/S1041610201007517.

25. Kaufer DI, Cummings $\mathrm{JL}$, Ketchel P, Smith V, MacMillan A, Shelley T, Lopez OL, DeKosky ST. Validation of the NPI-Q, a Brief Clinical Form of the Neuropsychiatric Inventory. J Neuropsychiatry Clin Neurosci. 2000;12(2):23339. doi:10.1176/jnp.12.2.233.

26. Yeh TL, Liao IC, Yang YK, Ko HC, Chang CJ, Lu FH. Geriatric Depression Scale (Taiwanese and Mandarin Translations). Clin Gerontol. 1995;15(3):58-60. 
27. Meguro K, SENAHA ML, Caramelli P, Ishizaki J, Chubacci R, Meguro M, et al. Language deterioration in four Japanese-Portuguese bilingual patients with Alzheimer's disease: a trans-cultural study of Japanese elderly immigrants in Brazil. Psychogeriatrics. 2003;3(2):63-8.

28. Friedland D, Miller N. Language Mixing in Bilingual Speakers with Alzheimer's Dementia: A Conversation Analysis Approach. Aphasiology. 1999;13(4-5):427-44. doi:10.1080/026870399402163.

29. Jing-Jy W, Wen-Yun C, Pei-Ru L, Ming-Chyi P. Delusions and Underlying Needs in Older Adults with Alzheimer's Disease: Influence of Earlier Life Experiences and the Current Environment. J Gerontol Nurs. 2014;40(12):38-47.

30. Machado A, Herrera AJ, de Pablos RM, Espinosa-Oliva AM, Sarmiento M, Ayala A, Venero JL, et al. Chronic Stress as a Risk Factor for Alzheimer's Disease. Rev Neurosci. 2014;25(6):785-804. doi:10.1515/revneuro-2014-0035.

31. Johansson L, Guo X, Waern M, Ostling S, Gustafson D, Bengtsson C, Skoog I. Midlife Psychological Stress and Risk of Dementia: A 35-Year Longitudinal Population Study. Brain. 2010;133(8):2217-24. doi:10.1093/brain/awq116.

32. Rothman SM, Mattson MP. Adverse Stress, Hippocampal Networks, and Alzheimer's Disease. NeuroMolecular Med. 2010;12(1):56-70. doi:10.1007/s12017-009-8107-9.

33. Taragano FE, Allegri RF, Krupitzki H, Sarasola DR, Serrano CM, Loñ L, Lyketsos CG. Mild Behavioral Impairment and Risk of Dementia: A Prospective Cohort Study of 358 Patients. Int J Geriatr Psychiatry. 2009;70(4):584-92. doi:10. 4088/JCP.08m04181.

34. Geda YE, Schneider LS, Gitlin LN, Miller DS, Smith GS, Bell J, Evans J, et al. Neuropsychiatric Symptoms in Alzheimer's Disease: Past Progress and Anticipation of the Future. Alzheimers Dement. 2013:9(5):602-8. doi:10.1016/j.jalz.2012.12.001.

\section{Submit your next manuscript to BioMed Central and we will help you at every step:}

- We accept pre-submission inquiries

- Our selector tool helps you to find the most relevant journal

- We provide round the clock customer support

- Convenient online submission

- Thorough peer review

- Inclusion in PubMed and all major indexing services

- Maximum visibility for your research

Submit your manuscript at www.biomedcentral.com/submit 